\title{
Functional Duality of Astrocytes in Myelination
}

\author{
Besma Nash, ${ }^{1}$ Christine E. Thomson, ${ }^{2}$ Christopher Linington, ${ }^{1}$ Ariel T. Arthur, ${ }^{1}$ John D. McClure, ${ }^{3}$ \\ Martin W. McBride, ${ }^{3 *}$ and Susan C. Barnett ${ }^{1 *}$ \\ ${ }^{1}$ Glasgow Biomedical Research Centre, Institute of Infection, Immunity, and Inflammation, University of Glasgow, Glasgow G12 8TA, United Kingdom, \\ ${ }^{2}$ Comparative Physiology and Anatomy, Massey University, Palmerston, North, New Zealand, and ${ }^{3}$ BHF (British Heart Foundation) Cardiovascular \\ Research Centre, Institute of Cardiovascular and Medical Sciences, University of Glasgow, Glasgow G12 8QQ, United Kingdom
}

Astrocytes undergo major phenotypic changes in response to injury and disease that directly influence repair in the CNS, but the mechanisms involved are poorly understood. Previously, we have shown that neurosphere-derived rat astrocytes plated on poly-L-lysine (PLL-astrocytes) support myelination in dissociated rat spinal cord cultures (myelinating cultures). It is hypothesized that astrocyte reactivity can affect myelination, so we have exploited this culture system to ascertain how two distinct astrocyte phenotypes influence myelination. Astrocytes plated on tenascin C (TnC-astrocytes), a method to induce quiescence, resulted in less myelinated fibers in the myelinating cultures when compared with PLL-astrocytes. In contrast, treatment of myelinating cultures plated on PLL-astrocytes with ciliary neurotrophic factor (CNTF), a cytokine known to induce an activated astrocyte phenotype, promoted myelination. CNTF could also reverse the effect of quiescent astrocytes on myelination. A combination of microarray gene expression analysis and quantitative real-time PCR identified CXCL10 as a potential candidate for the reduction in myelination in cultures on TnC-astrocytes. The effect of TnC-astrocytes on myelination was eliminated by neutralizing CXCL10 antibodies. Conversely, CXCL10 protein inhibited myelination on PLL-astrocytes. Furthermore, CXCL10 treatment of purified oligodendrocyte precursor cells did not affect proliferation, differentiation, or process extension compared with untreated controls, suggesting a role in glial/axonal ensheathment. These data demonstrate a direct correlation of astrocyte phenotypes with their ability to support myelination. This observation has important implications with respect to the development of therapeutic strategies to promote CNS remyelination in demyelinating diseases.

\section{Introduction}

Astrocytes are the most abundant glial cell of the CNS and play multiple roles in organizing and maintaining brain structure and function (Maragakis and Rothstein, 2006; Sofroniew and Vinters, 2010). In the normal, uninjured CNS, astrocytes are often termed nonactivated, normal, or quiescent, although they are thought to play functional roles (Eddleston and Mucke, 1993; Holley et al., 2005). However, after injury or disease, their properties change dramatically, where they undergo gliosis/anisomorphic astrocytosis to acquire a reactive phenotype (Eddleston and Mucke, 1993; Liberto et al., 2004). This reactive astrocytic response is associated with cellular hypertrophy, proliferation, process extension and interdigitation, and increased production of glial fibrillary acidic protein (GFAP), vimentin, nestin, heparan sulfate proteoglycans, chondroitin sulfate proteoglycans, and growth factors (Eng and Ghirnikar, 1994; Norenberg, 1994;

Received March 22, 2011; revised May 5, 2011; accepted May 9, 2011.

Author contributions: S.C.B. designed research; B.N., A.T.A., and M.W.M. performed research; B.N., J.D.M., M.W.M., and S.C.B. analyzed data; B.N., C.E.T., C.L., M.W.M., and S.C.B. wrote the paper.

This work was funded by the Multiple Sclerosis Society of Great Britain. We thank Dr. Andreas Faissner, RuhrUniversity, Bochum, Germany, for the TnC antibody, and Wendy Crawford for technical help with the microarray [BHF (British Heart Foundation), University of Glasgow]. We also are grateful for the technical help from Dr. Jen Higginson and Huyla Kiray to complete some of the experiments.

${ }^{*}$ M. W. McBride and S. C. Barnett share senior authorship.

Correspondence should be addressed to Professor Sue Barnett, Institute of Infection, Immunity and Inflammation, College of Medical, Veterinary and Life Sciences, Glasgow Biomedical Research Centre, Room B329, 120 University Place, University of Glasgow, Glasgow G12 8TA, UK. E-mail: Susan.Barnett@glasgow.ac.uk.

DOI:10.1523/JNEUROSCI.1449-11.2011

Copyright $\odot 2011$ the authors $\quad 0270-6474 / 11 / 3113028-11 \$ 15.00 / 0$
Gómez-Pinilla et al., 1995; McKeon et al., 1999; Leadbeater et al., 2006). Ultimately, this may progress to formation of glial scar tissue, a response that can be beneficial, for example, by encapsulating infections and areas of tissue necrosis, restoring bloodbrain barrier integrity, or excluding non-neural cells from the CNS (Eddleston and Mucke, 1993), but also detrimental. In particular, formation of glial scar tissue is associated with failure of remyelination and axonal regeneration (Silver and Miller, 2004; Pekny and Nilsson, 2005; Nair et al., 2008).

It is now recognized that astrocytes in vivo can also undergo a spectrum of phenotypic and functional changes associated with improved tissue remodeling and recovery (Faulkner et al., 2004; Liberto et al., 2004; Sofroniew and Vinters, 2010). These beneficial responses occur at sites distant from severe injury or in response to a milder CNS trauma (Fernaud-Espinosa et al., 1993; Sofroniew and Vinters, 2010). These astrocytes are termed "activated" and become hypertrophic, acquire a more stellate morphology, and secrete a variety of enzymes, growth and trophic factors, and antioxidants (Liberto et al., 2004). This state of activated/isomorphic gliosis is thought to be induced by specific cytokines including ciliary neurotrophic factor (CNTF) and interleukin-1 $\beta$ (Hudgins and Levison, 1998; Albrecht et al., 2003), and, unlike the permanent changes associated with reactive astrocytosis and scar formation, the characteristics of the activated astrocyte phenotype are believed to be reversible.

In the context of their ability to support demyelinated lesions to (re)myelinate, astrocyte behavior is critical and complex (Williams et al., 2007; Sofroniew, 2009; Sofroniew and Vinters, 2010). 
Astrocytes have a major influence on remyelination in vivo as demonstrated by the observation that oligodendrocytes preferentially remyelinate axons in areas containing astrocytes (Blakemore and Crang, 1989; Franklin et al., 1991; Jasmin and Ohara, 2002; Talbott et al., 2005). Similarly, transplantation of astrocytes into demyelinated lesions enhanced endogenous remyelination (Franklin et al., 1991). These in vivo observations were recapitulated in vitro in our studies demonstrating that astrocytes are a prerequisite to promote myelination by rat spinal cord cells (Sørensen et al., 2008). These studies confirmed that astrocytes secrete important, promyelinating factors. We have now used these cultures to investigate how factors that polarize astrocytes to induce a quiescent or reactive/activated phenotype influence myelination. We show that the phenotype of astrocytes has a crucial role in determining their effects on myelination.

\section{Materials and Methods}

\section{Cell culture}

Generating monolayers. Neurospheres were generated from striata of Sprague Dawley rats of either sex aged $<36 \mathrm{~h}$ [based on the methods of Reynolds and Weiss (1996) and Zhang et al. (1998) and described in detail by Sørensen et al. (2008)]. Enzymatically dissociated cells were resuspended in $20 \mathrm{ml}$ of neurosphere medium (NSM) consisting of DMEM/F12 (1:1, DMEM containing $4500 \mathrm{mg} / \mathrm{L}$ glucose), supplemented with $0.105 \% \mathrm{NaHCO}_{3}, 2 \mathrm{~mm}$ glutamine, $5000 \mathrm{IU} / \mathrm{ml}$ penicillin, $5 \mu \mathrm{g} / \mathrm{ml}$ streptomycin, $5.0 \mathrm{~mm}$ HEPES, $0.0001 \%$ bovine serum albumin (all from Invitrogen), $25 \mu \mathrm{g} / \mathrm{ml}$ insulin, $100 \mu \mathrm{g} / \mathrm{ml}$ apotransferrin, $60 \mu \mathrm{M} \mathrm{pu}-$ trescine, $20 \mathrm{~nm}$ progesterone, and $30 \mathrm{~nm}$ sodium selenite (all from Sigma), and plated into a $75 \mathrm{~cm}^{3}$ tissue culture flask (Greiner), supplemented with $20 \mathrm{ng} / \mathrm{ml}$ mouse submaxillary gland epidermal growth factor (EGF) (R\&D Systems), and maintained at $37^{\circ} \mathrm{C}$ in a humidified atmosphere of $7 \% \mathrm{CO}_{2} / 93 \%$ air. Every $2-3 \mathrm{~d}, 5 \mathrm{ml}$ of NSM and $4 \mu \mathrm{l}$ of EGF were added to the flask. When the spheres were large enough, they were triturated into fresh medium and plated into a flask for a further 24 $\mathrm{h}$. The spheres were then differentiated into astrocytes as previously described (Thomson et al., 2006). Briefly, the spheres were plated onto poly-L-lysine (PLL) (13 $\mu \mathrm{g} / \mathrm{ml}$, Sigma)-coated coverslips (13 $\mathrm{mm}$ diameter; VWR International) to generate the standard support for myelination (PLL-astrocytes or PLL-As) or onto tenascin-C (TnC) $(5 \mu \mathrm{g} / \mathrm{ml})$-coated coverslips to generate a quiescent astrocyte monolayer (TnC-astrocytes or TnC-As) (Holley et al., 2005). The monolayers were maintained in low-glucose DMEM supplemented with $10 \%$ fetal bovine serum (FBS) and $2 \mathrm{~mm} \mathrm{~L}$-glutamine (both from Sigma) for 7-10 d until confluent.

Olfactory ensheathing cells (OECs) were isolated from the olfactory bulb of 7-d-old Sprague Dawley pups of either sex and purified using magnetic beads (Higginson and Barnett, 2011) (STEMCELL Technologies) and the $75^{\text {NTR }}$ antibody (Abcam). The cells were grown in serumfree, low-glucose DMEM modified as described by Bottenstein et al. (1979) (DMEM-BS, $1000 \mathrm{mg} / \mathrm{ml}$ glucose) (Bottenstein et al., 1979) with $5 \%$ FBS and further supplemented with fibroblast growth factor 2 (FGF2) ( $500 \mathrm{ng} / \mathrm{ml}$, Peprotech), heregulin $\beta-1$ ( $50 \mathrm{ng} / \mathrm{ml}$, R\&D Systems), forskolin $\left(5 \times 10^{-7} \mathrm{M}\right.$ Sigma), and astrocyte conditioned medium (1:5, fresh DMEM-BS taken after incubation with a confluent astrocyte monolayer for 48 h) (Noble and Murray, 1984; Alexander et al., 2002). The cells were grown on PLL-coated coverslips and used either as supporting monolayers or to condition medium shared with spinal cord myelinating cultures.

Myelinating cultures. The method of generating myelinating spinal cord cultures is based on that developed for mice (Thomson et al., 2008) and rats (Sørensen et al., 2008), with some modifications. Sprague Dawley rats of either sex were time mated, and embryos were used on embryonic day 15.5 (E15.5). The spinal cords (5-6) were dissected, cleared of meninges, minced with a scalpel blade, and enzymatically dissociated with trypsin (100 $\mu \mathrm{l}, 2.5 \%$, Invitrogen) and collagenase (100 $\mu \mathrm{l}, 1.33 \%$, ICN Pharmaceuticals) in HBSS (without calcium and magnesium). Enzymatic activity was stopped by adding $1 \mathrm{ml}$ of a solution containing 0.52 $\mathrm{mg} / \mathrm{ml}$ soybean trypsin inhibitor, $3.0 \mathrm{mg} / \mathrm{ml}$ bovine serum albumin, and $0.04 \mathrm{mg} / \mathrm{ml}$ DNase (Sigma) to prevent cell clumping. The cells were triturated, centrifuged, and resuspended in plating medium (PM) (50\% DMEM, 25\% horse serum, 25\% HBSS with calcium and magnesium), and 150,000 cells per $100 \mu \mathrm{l}$ were plated on PLL-As, TnC-As, or confluent monolayers of OECs. The coverslips were placed in a $35 \mathrm{~mm}$ Petri dish (2 per dish) and left in the incubator to attach for $2 \mathrm{~h}$. A combination of $300 \mu \mathrm{l}$ of PM and $500 \mu \mathrm{l}$ of differentiation medium (DM) (Thomson et al., 2006), which contained DMEM ( $4500 \mathrm{mg} / \mathrm{ml}$ glucose), $10 \mathrm{ng} / \mathrm{ml}$ biotin, $0.5 \%$ hormone mixture $(1 \mathrm{mg} / \mathrm{ml}$ apotransferrin, $20 \mathrm{~mm}$ putrescine, $4 \mu \mathrm{M}$ progesterone, and $6 \mu \mathrm{M}$ selenium (formulation based on N2 mix of Bottenstein and Sato, 1979), 50 nm hydrocortisone, and 0.1 $\mu \mathrm{g} / \mathrm{ml}$ insulin (all reagents from Sigma) was added. After $12 \mathrm{~d}$ in culture, the insulin was removed from the DM. Cultures were fed every $2 \mathrm{~d}$ by removing $500 \mu \mathrm{l}$ of medium and replacing it with fresh DM. On day 12 , conditions were applied as follows: CNTF at $2 \mathrm{ng} / \mathrm{ml}$ (Peprotech) or concentrations ranging between $0.02 \mathrm{pg} / \mathrm{ml}$ and $20 \mathrm{ng} / \mathrm{ml}$, CXCL10 neutralizing antibody at $2.0 \mu \mathrm{g} / \mathrm{ml}$ (R\&D Systems), CXCL10 (10 ng, Peprotech), or IgG1 myeloma protein as a control $(0.2 \mu \mathrm{g} / \mathrm{ml}$, Sigma).

Conditioning of E15.5 myelinating cultures. In several experiments we used a confluent monolayer of cells (OECs, PLL-As, TnC-As) to condition the medium supporting the myelinating cultures. This procedure involved incubating these cells grown on coverslips in the same Petri dish as the myelinating culture. Diagrams can be seen in Figure 3 (see below). For example, to determine whether OEC conditioned medium (CM) can directly influence myelination, two coverslips containing confluent monolayers of OECs were placed in the same $35 \mathrm{~mm}$ Petri dish as the myelinating cultures. This meant that OECs continuously secreted soluble factors into the medium and alleviated problems of adding reproducible concentrations of factors. In some experiments, PLL-As were pretreated with $2 \mathrm{ng} / \mathrm{ml} \mathrm{CNTF}$ for $24-48 \mathrm{~h}$, washed three times in PBS, and placed in the same dish as myelinating cultures plated on PLLastrocytes or TnC-astrocytes. CNTF-pretreated astrocytes were continually generated so that fresh CNTF-astrocytes could be replaced in the Petri dish at every feed.

\section{Oligodendrocyte precursor cell purification and treatment}

Cortical astrocytes were prepared from cerebral cortices of 1-d-old Sprague Dawley rat pups of either sex as described previously (Noble and Murray, 1984). The cells were maintained in DMEM-FBS and grown to confluency. The flasks were then shaken at $150 \mathrm{rpm}$ for $1-2 \mathrm{~h}$ to displace oligodendrocyte precursor cells (OPCs). The medium was collected and centrifuged [ $800 \mathrm{rpm}, 136 \mathrm{RCF}$ (relative centrifugal force) for $5 \mathrm{~min}$ ] and resuspended in DMEM-BS. The cells were plated onto PLL-coated coverslips and supplemented with FGF2 (10-20 ng/ml) and PDGF (10-20 $\mathrm{ng} / \mathrm{ml}$ ) for $5 \mathrm{~d}$. The growth factors were then withdrawn for $3 \mathrm{~d}$. OPCs were treated with CXCL10 $(10 \mathrm{ng} / \mathrm{ml})$ every other day for 8 consecutive days. For proliferation experiments, bromodeoxyuridine (BrdU) (Dako, $10 \mu \mathrm{M}$ ) was added for $18-24 \mathrm{~h}$ before fixation and visualized by indirect immunofluorescence with anti-BrdU (IgG1, Dako) on day 4 (see below for details). For differentiation experiments, OPCs were fixed and immunolabeled on day 8 with the O4 antibody, A2B5, anti-MOG, and anti-MBP antibody (for details, see Immunocytochemistry and antibodies, below).

\section{Immunocytochemistry and antibodies}

Neurites were visualized using a monoclonal antibody against phosphorylated neurofilament (SMI-31, anti-mouse IgG1, 1:1500; Covance Cambridge Bioscience). Mature myelin was visualized using the AA3 antibody (1:100, anti-rat) (Yamamura et al., 1991), which labels PLP/ DM20 proteins. Monolayers of astrocytes were visualized using antiGFAP (1:500, anti-rabbit, Dako). To assess reactivity, an antibody against the intermediate filament protein nestin was used $(1: 100$, anti-mouse IgG1, Millipore Bioscience Research Reagents). Anti-TnC was used to visualize extracellular TnC (1:1000, anti-rabbit; gift from Andreas Faissner, Ruhr University, Bochum, Germany). The O4 antibody (1:1 hybridoma, anti-mouse IgM) (Sommer and Schachner, 1981) and A2B5 (1:1 hybridoma, anti-mouse, IgM; gift from Professor Mark Noble, University of Rochester, Rochester, NY) (Abney et al., 1983) were used to visualize purified OPCs, while MBP (1:200, anti-mouse, IgG2a, Milli- 
pore) and MOG (1:100, anti-mouse, IgG2a) (Piddlesden et al., 1993) were used to visualize mature oligodendrocytes.

For surface labeling, primary antibodies (diluted in DMEM) were applied and left for 20-30 min at room temperature. The cultures were then washed in PBS and the secondary antibody (diluted in DMEM) was added for 20-30 min. After washing, the cells were fixed in 4\% paraformaldehyde for $15 \mathrm{~min}$. For colabeling with most of the cytosolic antigens, cells were permeabilized with $0.5 \%$ Triton X-100 for 15 min and blocked using blocking buffer (containing PBS with $0.1 \%$ Triton X-100, $0.2 \%$ gelatin) for $15 \mathrm{~min}$. Primary antibodies, diluted with blocking buffer, were added to the cultures for $1-2 \mathrm{~h}$ at room temperature or overnight at $4^{\circ} \mathrm{C}$. For monolayers of astrocytes, ice-cold methanol was added and left for $15 \mathrm{~min}$ at $-20^{\circ} \mathrm{C}$ for fixation and permeabilization. The coverslips were then washed in PBS and the appropriate primary antibodies, followed by the appropriate fluorochrome-conjugated secondary antibodies, added for $45 \mathrm{~min}$ at room temperature (Southern Biotech). The coverslips were then washed in PBS, followed by $\mathrm{dH}_{2} \mathrm{O}$, and mounted in Vectashield (Vector Laboratories).

For BrdU immunoreactivity, to assess cell proliferation, the cells were incubated with BrdU (Dako, $10 \mu \mathrm{M}$ ) for 18-24 h before fixation in ice-cold methanol at $-20^{\circ} \mathrm{C}$ for $15 \mathrm{~min}$, followed by a 1 min fixation with $0.1 \%$ paraformaldehyde. Sodium hydroxide, $0.07 \mathrm{M}$, was then added for $15 \mathrm{~min}$, followed by anti-BrdU (1:20, anti-mouse IgG1, Dako) made up in PBSTween, $0.5 \%$, for $30 \mathrm{~min}$. The appropriate fluorochrome-conjugated secondary antibodies were added for $45 \mathrm{~min}$ at room temperature (Southern Biotech). The cells were washed with PBS-Tween, $0.5 \%$, between steps.

Imaging. Cells were imaged using an Olympus BX51 fluorescent microscope and images were captured using Image-Pro software. For quantitative analysis of neurite density and myelination, 10 images from each coverslip were taken at random at $10 \times$ magnification. Each condition for each experiment was performed in duplicate; therefore, 20 images were taken per condition per experiment, and experiments were performed in triplicates. Thus, a total of 60 images for each condition were used for quantification and analysis.

Quantitative analysis for neurite density and myelination. Neurite density was measured using NIH ImageJ software (version 1.45). The pixel value of the SMI-31 reactivity was measured as a percentage of the total pixel value in one image (total area). The AA3 antibody (anti-PLP/DM20) recognizes both myelin sheath and oligodendrocyte cell bodies, thus making it difficult to look at PLP/DM20 immunoreactivity alone to calculate the percentage of myelinated axons. Therefore, it was essential to manually identify and draw along the myelinated sheaths using Adobe Photoshop (Elements 7.0) and brush shape size 9, using a pure blue color. To calculate the percentage of myelinated axons, the number of pixels where there is an overlap of blue and green is calculated as percentage of the total SMI-31 pixel reactivity (Sørensen et al., 2008). For comparison of values between groups of conditions, data were analyzed by calculating ratios and analyzing these with one-sample Student's $t$ tests, using 1 as the null hypothesis mean (or 0 when data are logged). The mean of a minimum of 3 experiments per condition was calculated, and all values were expressed as means \pm SEM. Significance was represented using $p$-values, where values $<0.05$ were considered significant, and are indicated by an asterisk on images.

Characterization of astrocytes, oligodendrocyte area, and neurite thickness. To calculate nestin reactivity, images within one experiment were taken at the same threshold for all conditions. Ten images per condition for each experiment were taken. Using NIH ImageJ software, a freehand selection was made around each cell, and inte-
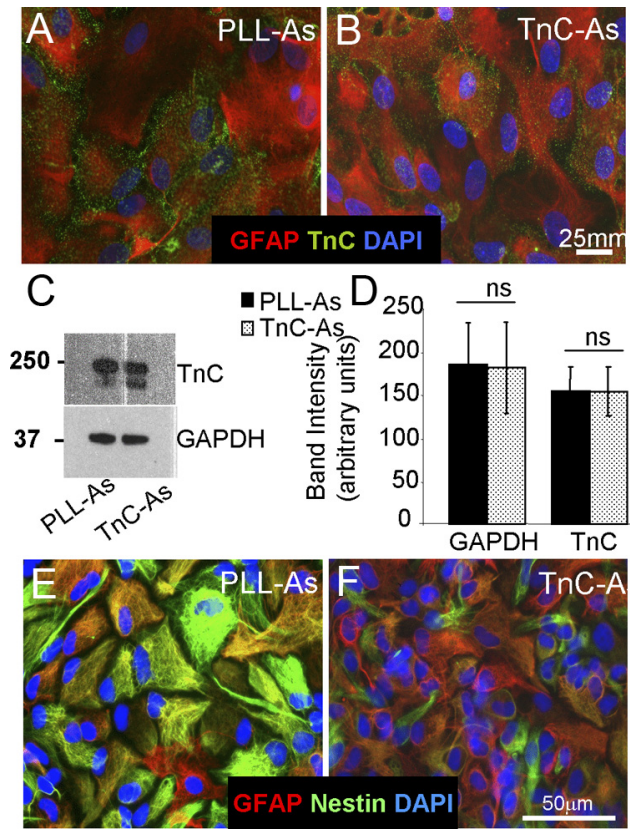

Figure 1. Biological properties of astrocytes plated on $\operatorname{TnC}$ compared with astrocytes plated on PLL. $\boldsymbol{A}, \boldsymbol{B}, \mathrm{PLL}-\mathrm{As}(\boldsymbol{A})$ or TnC-As $(\boldsymbol{B})$ were fixed and immunostained for GFAP, TnC, and DAPI. $\boldsymbol{C}, \boldsymbol{D}$, Sister astrocyte cultures were lysed and immunoblotted for TnC and GAPDH expression (C), and the intensity of the Western blots was quantified from three experiments $(\boldsymbol{D})$. TnC-As did not express higher levels of TnC compared with PLL-As. E, F, PLL-As and TnC-As were immunolabeled with anti-GFAP, nestin, and DAPI.
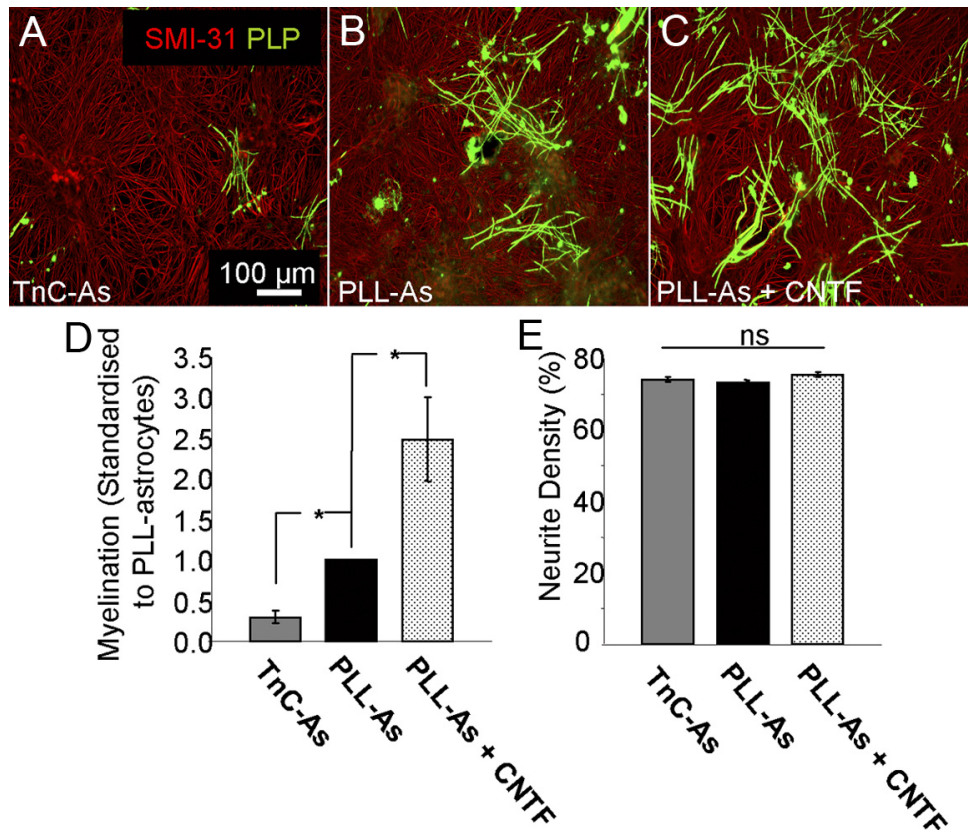

Figure 2. Myelination was reduced on quiescent astrocytes. $\boldsymbol{A}-\boldsymbol{C}$, Myelinating cultures were plated on PLL-As $(\boldsymbol{A})$ or $\operatorname{TnC}-\operatorname{As}(\boldsymbol{B})$. PLL-As were treated with $2 \mathrm{ng} / \mathrm{ml}$ CNTF from day 12 onward (C). D, Myelination was significantly higher on PLL-As compared with those plated on TnC-As. Treatment of cultures on PLL-As with CNTF resulted in a significant increase in myelination compared with untreated PLL-As. E, Neurite density was similar in all conditions. ${ }^{*} p<0.05$.

grated density and size were measured. The integrated intensity was measured as ratio of the cell size. To count proliferating cells, the cell counter feature from NIH ImageJ (version 1.45) was used. The number of proliferating astrocytes $\left(\mathrm{GFAP}^{+} / \mathrm{BrdU}^{+}\right)$was expressed as a percentage of the total DAPI count. To count nestin-positive astrocytes, GFAP- and nestin-positive cells were counted and expressed as a percentage of the total DAPI count. 

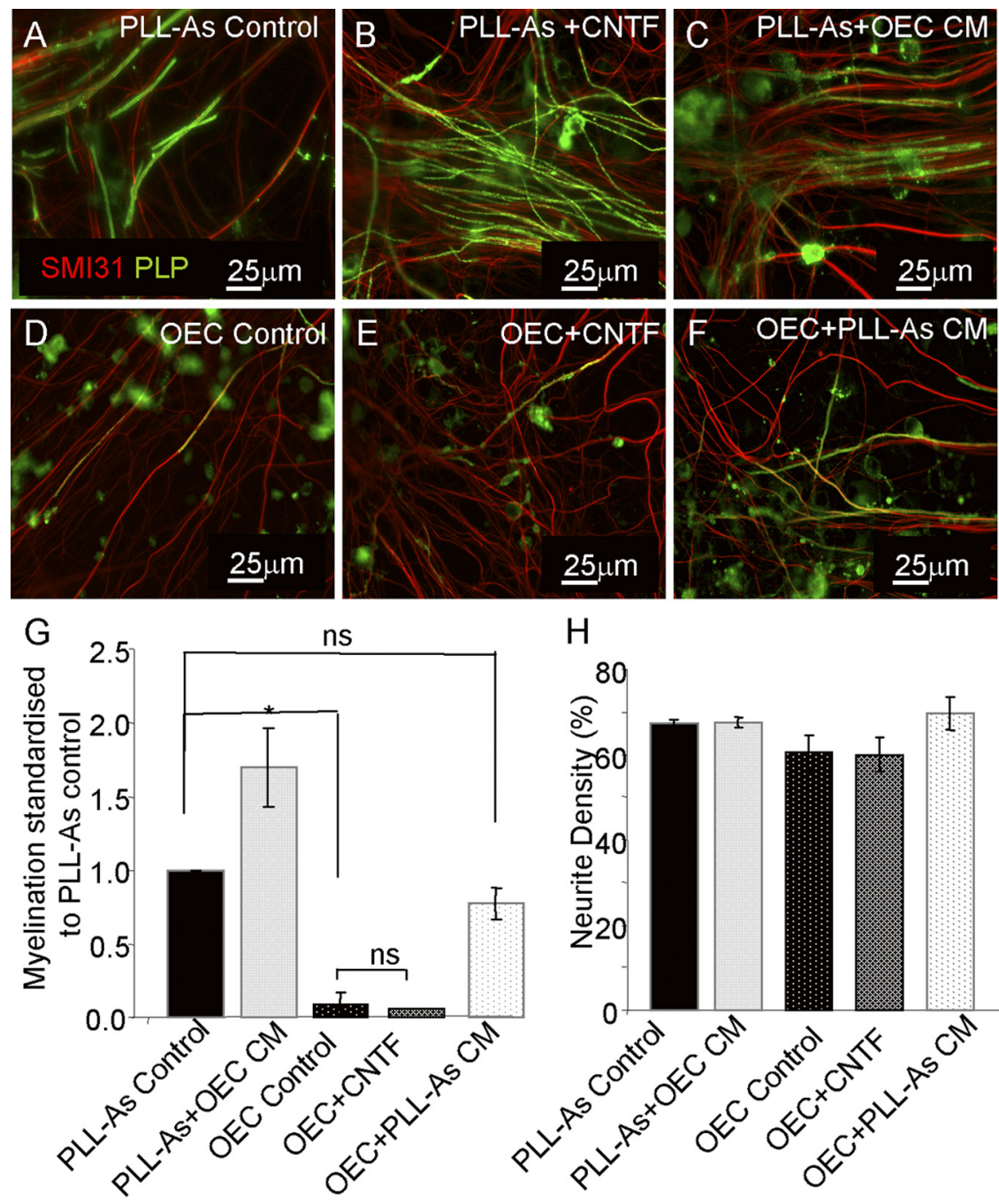

$\mathrm{H}$
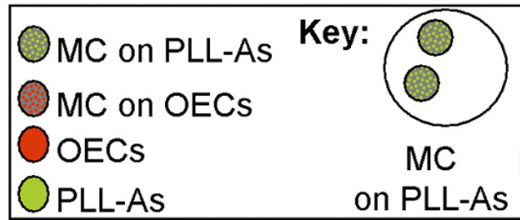

on PLL-As
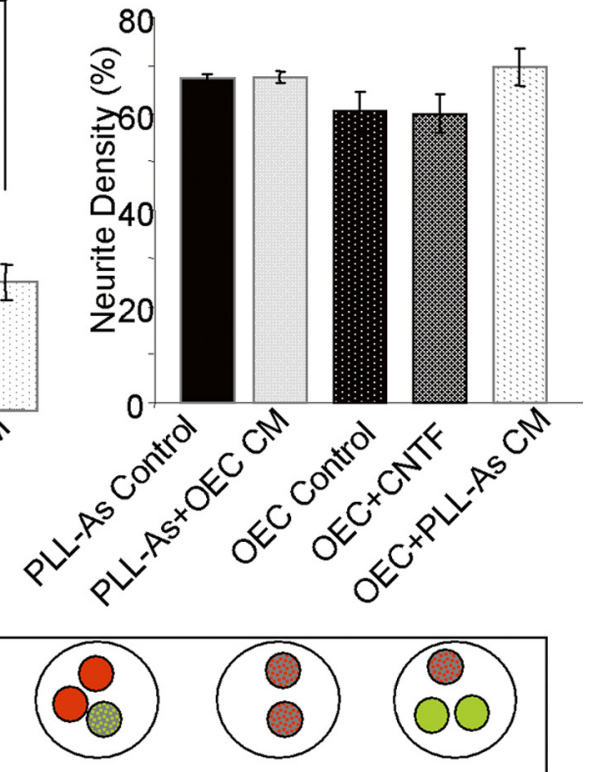

Figure 3. CNTF does nothave a promyelinating effect when cultures are plated on a monolayer of $0 \mathrm{E} C \mathrm{~S}$. $A-F$, Myelinating cultures were plated on PLL-As $(\boldsymbol{A}-\boldsymbol{C})$ or OECS $(\boldsymbol{D}-\boldsymbol{F})$ and left untreated $(\boldsymbol{A}, \boldsymbol{D})$ or treated with CNTF $(2 \mathrm{ng} / \mathrm{m})(\boldsymbol{B}, \boldsymbol{E})$. Monolayers of astrocyte (PLL-As) cultures were included in the same dish as myelinating cultures plated on an OEC monolayer to condition the medium supporting the myelinating cultures $(\boldsymbol{F})$ and, conversely, monolayers of OECs were placed in the same dish as myelinated cultures plated on a astrocyte monolayer (C). G, Cultures plated on a monolayer of OEC do not show the same increase in myelination with the addition of exogenous CNTF. Quantification of myelination showing a significant increase in cultures plated on OEC monolayers and conditioned by PLL-As. $\boldsymbol{H}$, Neurite density as a percentage of SMI-31 immunoreactivity for conditions shown in $\boldsymbol{A}-\boldsymbol{F}\left({ }^{*} p<0.05 ; \mathrm{ns}, p>0.05\right)$. MC, Myelinating cultures.

To assess whether oligodendrocyte process extension was affected by CXCL10 treatment, oligodendrocyte area was measured using ImageJ. The extent of oligodendrocyte process formation was calculated by measuring the area surrounding the nuclei, including the outermost tips occupied by processes. Ten images for each experimental repeat were used, and all MBP-positive cells in each image were measured.

Images for the measurement of neurite diameter were taken at $10 \times$ magnification. Ten images of each myelinating culture condition were taken at day 26. Each image was opened in ImageJ and a representative area was zoomed into 6 times. Using the Straight Line selection, a line was drawn across the diameter of the SMI-31-positive axons and arbitrary measurements were recorded. These were then converted into values (micrometers) using the scale bar on the image. A total of 30 images were taken for each

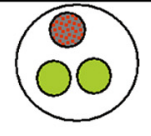

condition for 3 experimental repeats. For statistical analysis, values from all experiments were analyzed using an unpaired two-sample $t$ test.

\section{Western blotting}

Astrocyte monolayers were lysed using CelLytic M Cell Lysis Reagent (Sigma). Protein concentrations were measured and $10 \mu \mathrm{g}$ of total protein for each condition loaded into a NuPage 4-12\% Bis-Tris Gel (Invitrogen) with rainbow molecular-weight markers (GE Healthcare Life Sciences). The gel was transferred using the iBlot (Invitrogen), and membranes were blocked with $5 \%$ powdered milk in PBS and $0.1 \%$ Tween (PBST). Membranes were incubated with either polyclonal rabbit Tenascin C antibody (1:1000) or mouse monoclonal GAPDH (1:1000, Thermo Scientific) as a housekeeping gene in block plus PBST for $1 \mathrm{~h}$ at room temperature. The membrane was washed with PBST and incubated with the appropriate HRP-conjugated secondary antibody for $1 \mathrm{~h}$ at room temperature in block + PBST (anti-rabbit, 1:10,000, Santa Cruz Biotechnology; anti-mouse IgG1, 1:10,000, GE Healthcare Life Sciences). After three washes, the membranes were developed using enhanced chemiluminescence (GE Healthcare Life Sciences) and visualized using a Konica Minolta SRX101A imaging system. Densitometry was performed on the bands using ImageJ. For statistical analysis, a paired two-sample $t$ test was used on the densitometry arbitrary values, comparing band intensity of TnC-As to PLL-As for the GAPDH and TnC blots.

\section{RNA extraction}

The RNA of astrocytes plated on PLL or TnC, or treated with CNTF $(2 \mathrm{ng} / \mathrm{ml})$, was extracted at 4 and $24 \mathrm{~h}$ post-treatment using a Qiagen RNeasy Micro Kit, following the manufacturer's instructions, and RNA quality and integrity were checked using the Bioanalyzer 6000 Nano LabChip platform. RNA was used for quantitative reverse transcription (qRT)-PCR and microarray studies.

\section{Microarray analysis}

Two Illumina RatRef-12 Expression BeadChip microarrays were used to assess the gene expression of the 15 samples. These samples came from RNA generated from astrocytes plated in five different conditions: on PLL for 4 and $24 \mathrm{~h}$; on PLL+CNTF for 4 and $24 \mathrm{~h}$; on TnC for $4 \mathrm{~h}(n=$ 3 per group; astrocytes were derived from different groups of pups, each from a different outbred female). cRNA was hybridized using an Illumina TotalPrep RNA Amplification kit, according to the manufacturer's instructions. Briefly, RNA (250 ng) was reverse transcribed using Oligo(dT) primers, followed by second-strand synthesis and in vitro transcription to convert cDNA to cRNA. After a purification step, cRNA was made up to $750 \mathrm{ng}$. The Illumina RatRef-12 Expression BeadChip was incubated with assay samples at $58^{\circ} \mathrm{C}$ overnight for hybridization. After several washing and blocking steps, the samples were scanned with BeadArray Reader (Illumina). The data were quantile normalized in BeadStudio (Illumina) and Rank Products (Breitling et al., 2004; Breitling and Herzyk, 2005) was used to assess the statistical significance of pairwise intergroup differences. Significance was determined using the false discovery rate (FDR) multiple testing correction method (Benjamini and Hochberg, 1995), with a FDR cutoff of 5\%. Venn 
diagrams were used to look for consistent differences between TnCastrocytes and each of the other groups for $4 \mathrm{~h}$.

\section{$q R T-P C R$ verification}

Following RNA extraction, cDNA was synthesized using the Invitrogen SuperScript First-Strand Synthesis System and the manufacturer's guidelines. Cycling parameters were as follows: $65^{\circ} \mathrm{C}$ for $5 \mathrm{~min}, 25^{\circ} \mathrm{C}$ for 10 $\mathrm{min}, 50^{\circ} \mathrm{C}$ for $50 \mathrm{~min}, 85^{\circ} \mathrm{C}$ for $5 \mathrm{~min}$, and then $37^{\circ} \mathrm{C}$ for $20 \mathrm{~min}$. Realtime PCR was performed using a $20 \mu \mathrm{l}$ reaction volume containing SYBR Green, forward primer (f), reverse primer (r), distilled water, and the cDNA template $(2 \mathrm{ng} / \mathrm{ml})$. Primers were designed using the UCSC Genome Browser (http://genome.ucsc.edu/index.html) and Primer 3 (http:// frodo.wi.mit.edu/primer3/) (Rozen and Skaletsky, 2000), and were purchased from Sigma. Primers used include CXCL10 (f: 5'-TCGTGCTGCTGAGTCTGAGT-3'，r: 5'-CAACATGCGGACAGGATAGA-3'), connective tissue growth factor (CTGF) (f: 5'-GAGTCGCTCTGCATGGTCA-3', r: 5'-GCAGCCAGAAAGCTCAAACT-3'), and THBS4 (f: 5'-CTCGAGTGACAACAGCAAAC-3', r: 5'-CAGCTGCAGGTTGTTGAAAA- $\left.3^{\prime}\right)$. Plates with reactions were inserted into the Applied Biosystems Fast Real-Time PCR System (ABI 7900HT) using the following cycle settings: $95^{\circ} \mathrm{C}$ for $10 \mathrm{~min}, 40$ cycles of $95^{\circ} \mathrm{C}$ for $15 \mathrm{~s}$, followed by $60^{\circ} \mathrm{C}$ for $1 \mathrm{~min}, 95^{\circ} \mathrm{C}$ for $15 \mathrm{~s}, 60^{\circ} \mathrm{C}$ for $15 \mathrm{~s}$, and a final dissociation step at $95^{\circ} \mathrm{C}$ for $15 \mathrm{~s}$. Cycle threshold $\left(C_{\mathrm{t}}\right)$ was calculated based on GAPDH (endogenous control). GAPDH cycle thresholds were confirmed to be comparable across conditions. CXCL10, CTGF, and THBS4 were expressed relative to GAPDH in each sample condition derived using the comparative $\delta \delta C_{\mathrm{t}}$ threshold change method (relative quantification). For statistical analysis, a paired two-sample $t$ test was used on the mean $\delta C_{\mathrm{t}}$ for each experimental repeat.

\section{Results}

Astrocyte phenotype determines its ability to support myelination

We have previously shown that a monolayer of neurosphere-derived astrocytes plated on a PLL substrate promoted neuronal survival and myelination in rat mixed embryonic spinal cord cells (myelinating cultures) (Sørensen et al., 2008). To investigate whether the phenotypic status of the astrocyte can affect myelination, we plated neurospherederived astrocytes on tenascin-C (TnCastrocytes), a method known to induce quiescence in astrocytes (Holley et al., 2005). We first examined the biological characteristics of these astrocytes to confirm quiescence (Fig. 1). As TnC has been reported to directly affect OPC differentiation (Czopka et al., 2009), we assessed its expression in the astrocyte cultures by immunocytochemistry and Western blotting (Fig. $1 A-$ $D)$. We found that there was no detectable difference in $\mathrm{TnC}$ expression on the surface of the astrocyte. TnCastrocytes had similar proliferation rates compared with astrocytes plated on PLL using BrdU uptake (15\% compared with $18 \%$, n.s.), but those on TnC were smaller $\left(9 \times 10^{3} \mu \mathrm{m}^{2}\right.$ compared with $\left.14.5 \times 10^{3} \mu \mathrm{m}^{2}, p<0.05\right)$ and exhibited lower levels of nestin immunoreactivity when compared with those grown on PLL (Fig. $1 E, F$ ), and from measurements of the percentage of nestin-positive cells ( $42 \%$ compared with $63 \%, p<0.05)$ and nestin-integrated density (39\% compared with $52 \%, p<0.05)$. These two latter phenomena are both characteristic

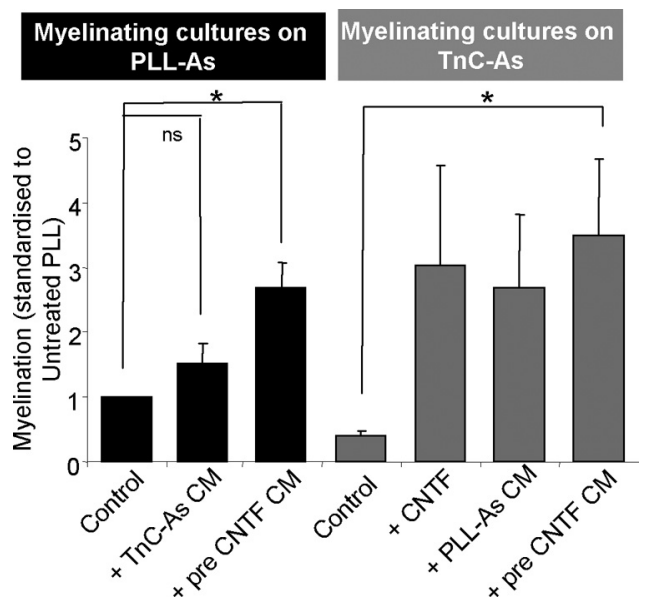

Figure 4. Activation of astrocytes by CNTF increases myelination. Myelinating cultures were plated onto PLL-As (black bars) or TnC-As (gray bars). CNTF treatment increased myelination in all cultures. When TnC-As were used to condition cultures plated on PLL-As, myelination was not affected, suggesting that the $\mathrm{TnC}$ effect is overcome by PLL-As. Conversely, cultures plated on TnC-As conditioned by coverslips of PLL-As promoted myelination. PLL-As pretreated with CNTF, washed, and then added to cultures resulted in an increase in myelination, suggesting the CNTF activates the astrocyte directly ( $\left.{ }^{*} p<0.05 ; \mathrm{ns}, p>0.05\right)$.
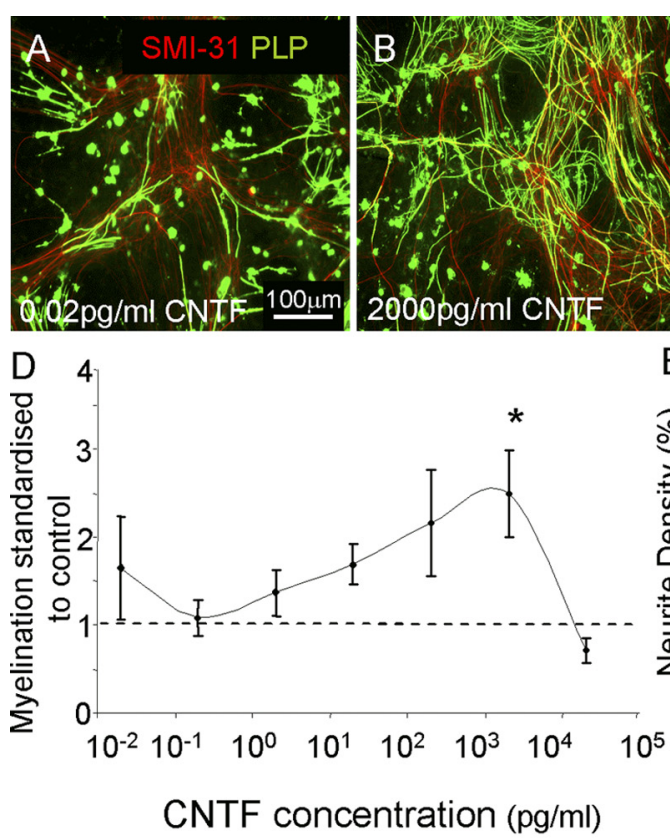

Figure 5. Titration of CNTF produced variable effects on myelination. $\boldsymbol{A}-\boldsymbol{C}$, E15.5 myelinating cultures were plated onto a confluent monolayer of astrocytes (PLL-As) and cultured for 26-28 d. On day 12, cultures were left untreated or treated with varying concentrations of CNTF $(0.02 \mathrm{pg}-20 \mathrm{ng} / \mathrm{ml})$. Representative figures of low, intermediate, and high concentrations in which low and high concentrations had no effect on myelination compared with control. $\boldsymbol{D}$, Graphical representation of the dosedependent effect on myelination by CNTF ( ${ }^{*} p<0.05$ vs control). Myelinated axons were calculated and standardized to controls for each respective experiment; the dotted line represents the standardized level for nontreated cultures. $\boldsymbol{E}$, Neurite density (assessed by SMI-31 reactivity) was unchanged at each concentration. of a shift toward a quiescent phenotype in accordance with the findings of Holley et al. (2005).

To assess the ability of quiescent astrocytes to support myelination, the myelinating cultures were plated on top of the $\mathrm{TnC}$ astrocytes. A significant decrease in myelination, but not neurite density, was seen when compared with myelinating cultures plated on PLL-astrocytes (Fig. 2, $p<0.05$ ). As TnC levels are similar on both astrocyte phenotypes, this is unlikely to be due to the direct 

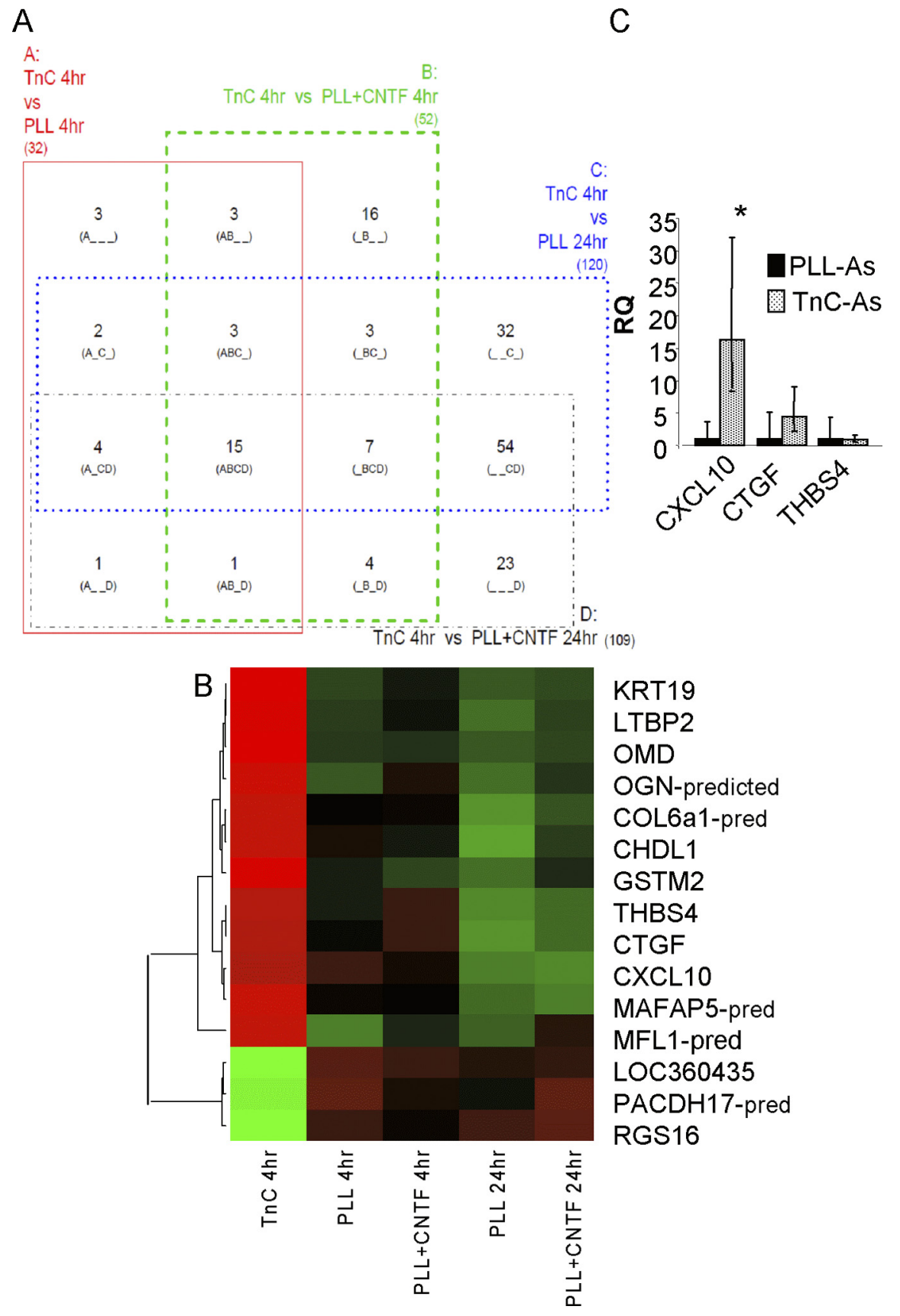

Figure 6. Candidate genes identified by microarray are verified via qRT-PCR. A, A four-way Venn diagram in which each rectangle ( $A, B, C$, and D) represents a pairwise comparison between $\operatorname{TnC}$-astrocytes after $4 \mathrm{~h}$ ( $\operatorname{TnC} 4 \mathrm{~h}$ ) and one of the other four conditions: PLL-astrocytes after $4 \mathrm{~h}$ (PLL $4 \mathrm{~h}$ ) and $24 \mathrm{~h}$ (PLL $24 \mathrm{~h})$, PLL-astrocytes treated with CNTF after $4 \mathrm{~h}$ (PLL+CNTF $4 \mathrm{~h}$ ) and $24 \mathrm{~h}$ (PLL + CNTF $24 \mathrm{~h}$ ). Each of the 15 segments indicates one particular intersection, e.g., "A_C_" contains the number of probes (genes) significantly different for the A (TnC $4 \mathrm{~h}$ vs PLL $4 \mathrm{~h}$ ) and C (TnC $4 \mathrm{~h}$ vs PLL $24 \mathrm{~h}$ ) comparisons but not the $B$ (TnC $4 \mathrm{~h}$ vs PLL + CNTF $4 \mathrm{~h}$ ) and D (TnC $4 \mathrm{~h}$ vs PLL + CNTF $24 \mathrm{~h}$ ) comparisons. Numbers shown indicate the number of significant genes (FDR $<0.05, n=3$ ) for each combination. $B$, Heatmap with dendrogram of the 15 probes significantly different in all four comparisons involving $\mathrm{TnC}$-astrocytes after $4 \mathrm{~h}$ ("ABCD" in Venn diagram). Green is low expression, red is high, black is intermediate; expression is standardized within each gene, and within-group median expression is shown. Dendrogram uses complete linkage and Euclidean distance. $C$, qRT-PCR, relative quantification (RQ) results for CXLCL10, CTGF, and THBS4. CXCL10 mRNA was significantly increased in TnC-astrocytes when compared with astrocytes treated with CNTF (Fig. $7 B)\left({ }^{*} p<0.05, n=3\right.$ ).

effect of TnC modulating OPC differentiation. Since CNTF has been reported to activate astrocytes, we treated the myelinating cultures plated on PLL-astrocytes with $2 \mathrm{ng} / \mathrm{ml} \mathrm{CNTF} \mathrm{(Liberto} \mathrm{et} \mathrm{al.,} \mathrm{2004).}$ CNTF treatment of cultures on PLL-astrocytes resulted in an increase in myelination (Fig. $2 C-E$ ). These data suggest that the reac- tivity status of the astrocyte monolayer determines the culture's ability to support myelination.

CNTF acts on the astrocyte monolayer It has been reported that CNTF treatment can promote OPC differentiation (Stankoff et al., 2002). For this reason, we wanted to assess whether CNTF was acting directly on OPCs or via activation of the astrocyte. To do this, we exploited our previous results obtained from plating myelinating cultures on OECs instead of an astrocyte monolayer (Sørensen et al., 2008). In these experiments, OECs supported neuronal survival and neurite extension, but not myelination, unless the cultures were continuously exposed to medium from a confluent monolayer of astrocytes placed in the same Petri dish [PLL-astrocyte conditioned medium (As CM)] (Sørensen et al., 2008) (Fig. 3D-F). Addition of CNTF to myelinating cultures plated on OECs did not lead to an increase in myelination when compared with untreated OEC cultures (Fig. $3 D, E$ ), indicating that CNTF did not have a direct effect on oligodendroglia. To determine whether this lack of response to CNTF was mediated by soluble factors secreted by OECs, we conditioned the medium of myelinating cultures plated on PLL-astrocytes by including two coverslips of confluent monolayers of OECs in the Petri dish (Fig. 3, key and OEC CM). This failed to identify any inhibitory effect of OEC conditioned medium on myelination (Fig. $3 C, G)$; conversely, myelination was actually increased compared with untreated controls. This suggests that OEC cell contact may play a role in preventing myelination; however, when these myelinating cultures plated on OEC monolayers were conditioned by coverslips of PLLastrocytes (PLL-As CM), myelination increased (Sørensen et al., 2008). Plating myelinating cultures on OEC and PLLastrocyte monolayers had no effect on neurite density (see Fig. 5H). These data support our view that an astrocyte-specific factor is responsible for myelination and suggests that the effect of CNTF on myelination is not due to a direct effect on OPCs/ oligodendrocytes but is mediated indirectly by affecting the supporting astrocyte monolayer which, in turn, affects myelination. This interpretation is supported by experimental results on cell proliferation using BrdU uptake, where we found that adding CNTF to these cultures had no effect on oligodendroglial cell proliferation. The numbers of proliferating cells were $0.8 \pm 0.23 \% \mathrm{O} 4 /$ $\mathrm{BrdU}^{+}$cells/field in untreated cultures versus $0.41 \pm 0.13 \%$ in CNTF-treated cultures ( $p>0.05$, data not shown). 
Table 1. Genes identified by microarray expression profiling

\begin{tabular}{|c|c|c|c|c|c|c|c|c|c|}
\hline \multirow[b]{2}{*}{ Probe_ID } & \multirow[b]{2}{*}{ ILMN_Gene } & \multicolumn{2}{|c|}{$\mathrm{A}: \operatorname{Tn}(4 \mathrm{~h} / \mathrm{PLL} 4 \mathrm{~h}$} & \multicolumn{2}{|c|}{$\begin{array}{l}\text { B: TnC } 4 \mathrm{~h} / \mathrm{PLL}+ \\
\text { CNTF } 4 \mathrm{~h}\end{array}$} & \multicolumn{2}{|c|}{ C: $\operatorname{TnC} 4$ h/PLL $24 \mathrm{~h}$} & \multicolumn{2}{|c|}{$\begin{array}{l}\text { D: TnC } 4 \mathrm{~h} / \mathrm{PLL}+ \\
\text { CNTF } 24 \mathrm{~h}\end{array}$} \\
\hline & & FDR & $\mathrm{FC}$ & FDR & $\mathrm{FC}$ & FDR & $\mathrm{FC}$ & FDR & $\mathrm{FC}$ \\
\hline ILMN_1373199 & KRT19 & 0.001 & 5.34 & 0.001 & 3.79 & 0.006 & 3.44 & 0.003 & 3.74 \\
\hline ILMN_1361640 & LTBP2 & 0.004 & 2.90 & 0.004 & 2.44 & 0.006 & 3.52 & 0.005 & 2.96 \\
\hline ILMN_1375112 & OMD & 0.006 & 2.80 & 0.003 & 2.72 & 0.007 & 3.17 & 0.005 & 2.96 \\
\hline ILMN_1350042 & THBS4 & 0.009 & 2.49 & 0.017 & 1.81 & 0.007 & 3.25 & 0.004 & 3.61 \\
\hline ILMN_1364113 & CTGF & 0.012 & 2.34 & 0.031 & 1.80 & 0.002 & 4.32 & 0.003 & 3.78 \\
\hline ILMN_1361636 & MLF1_PREDICTED & 0.004 & 2.32 & 0.017 & 1.75 & 0.012 & 2.50 & 0.015 & 2.14 \\
\hline ILMN_1364335 & CXCL10 & 0.009 & 2.12 & 0.017 & 2.00 & 0.006 & 3.37 & 0.004 & 3.62 \\
\hline ILMN_1352014 & OGN_PREDICTED & 0.038 & 2.05 & 0.027 & 1.81 & 0.026 & 2.39 & 0.015 & 2.23 \\
\hline ILMN_1365298 & MFAP5_PREDICTED & 0.026 & 2.00 & 0.017 & 2.05 & 0.009 & 2.91 & 0.006 & 3.01 \\
\hline ILMN_1349973 & CHRDL1 & 0.027 & 1.98 & 0.017 & 2.19 & 0.022 & 2.48 & 0.023 & 2.24 \\
\hline ILMN_1350896 & GSTM2 & 0.027 & 1.97 & 0.008 & 2.24 & 0.016 & 2.52 & 0.023 & 2.05 \\
\hline ILMN_1356949 & COL6A1_PREDICTED & 0.046 & 1.96 & 0.019 & 1.94 & 0.008 & 2.83 & 0.007 & 2.40 \\
\hline ILMN_1371157 & LOC360435 & 0.006 & -2.02 & 0.017 & -2.73 & 0.022 & -2.26 & 0.013 & -2.22 \\
\hline ILMN_1369130 & PCDH17_PREDICTED & 0.046 & -2.07 & 0.019 & -2.54 & 0.014 & -2.69 & 0.015 & -2.43 \\
\hline ILMN_1352018 & RGS16 & 0.045 & -2.08 & 0.049 & -1.77 & 0.028 & -2.11 & 0.045 & -1.85 \\
\hline
\end{tabular}

Results of the microarray experiment for the 15 probes significantly different (FDR $<0.05)$ in all four comparisons involving TnC-astrocytes after $4 \mathrm{~h}$. These correspond in the Venn diagram in Figure $7 \mathrm{~A}$ to segment "ABCD." Shown here are FDRs and fold changes (FC) for each of the four comparisons.

\section{CNTF-activated astrocytes promote myelination}

We have already established that treatment with CNTF increases myelination in cultures of PLL-As (Fig. 2, $p<0.05$ ). It is likely that this effect is due to the secretion of a soluble factor, since PLL-astrocytes pretreated with CNTF, washed, and then allowed to condition a myelinating culture on PLL-As also promoted myelination (Fig. 4, pre-CNTF CM). This conditioning by CNTF-treated PLL-astrocytes also promoted myelination in myelinating cultures plated on quiescent $(\mathrm{TnC})$ astrocytes. Interestingly, TnC-astrocytes allowed to condition myelinating cultures on PLL-astrocytes did not reduce myelination, presumably due to factors from the PLL-astrocytes being dominant over the negative effect of TnC-astrocytes. Thus, inhibition of myelination by TnC-astrocytes can be overcome by CNTF treatment and PLLastrocyte- secreted factors.

The CNTF effect was also shown to be dose dependent, where very low $(0.02 \mathrm{pg} / \mathrm{ml})$ and very high $(20 \mathrm{ng} / \mathrm{ml})$ doses had no effect on myelination (Fig. 5). CNTF treatment had no affect on neurite density (Fig. $5 E$ ) or neurite diameter $(1.6 \pm 0.16 \mu \mathrm{m}$ and $1.98 \pm 0.14 \mu \mathrm{m}$, respectively, $p>0.05$, paired $t$ test, data not shown). Thus, CNTF does not increase the likelihood of myelination due to increased axonal diameter (Duncan, 1934). However, we cannot exclude the possibility that CNTF may be acting directly on the axon to make it more "responsive" to being myelinated. The cytokine activation of astrocytes, via CNTF, may increase their ability to support myelination.

\section{TnC-As secrete factors that prevent myelination}

To identify the astrocyte-derived factors responsible for these effects, a series of microarray gene expression profiles was determined from five experimental groups, which are as follows: PLLastrocytes $4 \mathrm{~h}$, PLL-astrocytes $24 \mathrm{~h}$, PLL-astrocytes + CNTF $4 \mathrm{~h}$ and PLL-astrocytes + CNTF $24 \mathrm{~h}$, and TnC-astrocytes $4 \mathrm{~h}$. The results of these experiments are summarized in Figure 6 and Table 1 . Figure $6 A$ shows a four-way Venn diagram, with the segment of interest being "ABCD," as the 15 probes in it are significantly differentially expressed in TnC-astrocytes at $4 \mathrm{~h}$ compared with all four of the other astrocyte conditions (PLLastrocytes $4 \mathrm{~h}$, PLL-astrocytes $24 \mathrm{~h}$, PLL-astrocytes+CNTF $4 \mathrm{~h}$, and PLL-astrocytes + CNTF $24 \mathrm{~h}$ ). These 15 probes are detailed in Table 1, and in the heatmap in Figure $6 B$, showing how TnCastrocytes at $4 \mathrm{~h}$ are either consistently higher [positive fold change (FC) in Table 1; red in heatmap) or lower (negative FC, green) than the other conditions. This analysis identified several potential candidates, but we focused on three candidates that have previously been implicated in glial function and myelination, namely, CXCL10, CTGF, and THBS4. qRT-PCR was used to verify these three chosen genes, and the microarray result was confirmed for CXCL10 ( $p<0.05$ ); although not significant for CTGF and THBS4, the direction of change was consistent for both (Fig. 6C).

\section{CXCL10 and myelination}

To determine whether CXCL10 could be the candidate molecule responsible for the reduction in myelination on $\mathrm{TnC}$-astrocytes, we added neutralizing antibodies of CXCL10 to myelinating cultures plated on TnC-astrocytes or PLL-astrocytes (Fig. 7). For cultures plated on PLL-astrocytes, no significant effects were observed (Fig. $7 A, C, F$ ) and neurite density was similar in all treatments (data not shown). Conversely, addition of neutralizing antibodies of CXCL10 $(2 \mu \mathrm{g} / \mathrm{ml})$ to myelinating cultures plated on $\mathrm{TnC}$-astrocytes resulted in an increase in the percentage of myelinated fibers (Fig. $7 D-F, p<0.05)$. Using lower $(0.2 \mu \mathrm{g} / \mathrm{ml})$ and higher $(20 \mu \mathrm{g} / \mathrm{ml})$ concentrations of the CXCL10 antibodies also led to an increase in myelination, but not to the same extent as $2 \mu \mathrm{g} / \mathrm{ml}$ (data not shown). To address this effect further, we added CXCL10 directly to classical myelinating cultures plated on PLL-astrocytes. This led to a significant reduction in the percentage of axons ensheathed by myelin (Fig. 7 A, B,F). To examine the effect of CXCL10 directly on purified OPCs in the absence of axons, we treated purified OPCs with CXCL10 and assessed proliferation using BrdU uptake. CXCL10 did not affect OPC proliferation as there was no significant difference in the percentage of cells expressing BrdU (62\% for control cells compared with $60 \%$ for CXCL10-treated cells). Purified OPCs were treated with CXCL10 for $7 \mathrm{~d}$, and the percentages of cells labeled with the O4 antibody, A2B5, anti-MOG, and anti-MBP were calculated. It was found that there was no difference in the number of early and late OPC lineage cells in the presence of CXCL10 or any of the nonlabeled cells within the culture (Fig. $7 G$ ). In all experiments the percentage of contaminating GFAP-positive cells was $<10 \%$. The addition of CXCL10 to mature myelinating cultures ( $>$ day 28 ) did not affect the level of myelination, suggesting that it acts on oligodendrocytes in the process of myelination rather than mature 

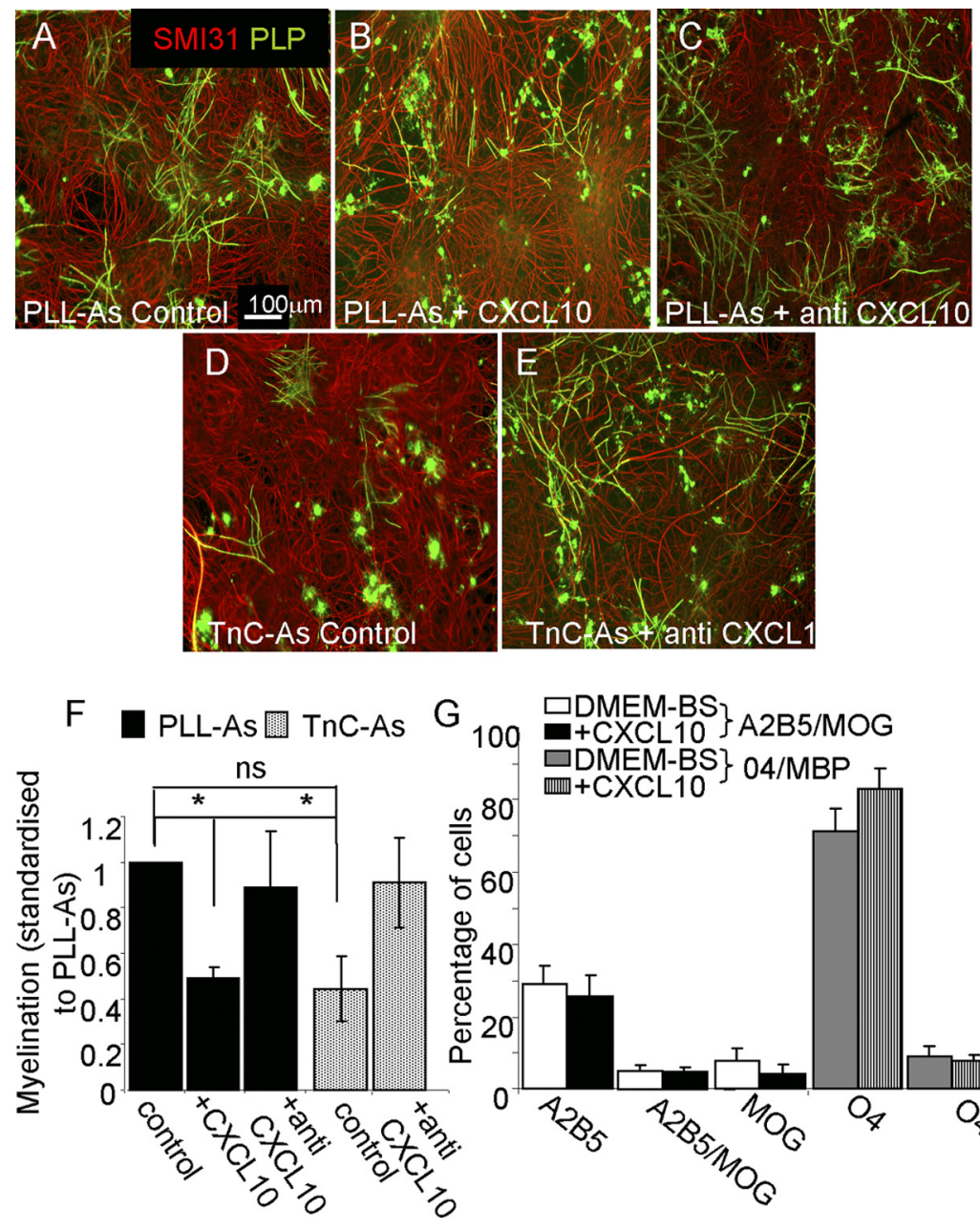
04/MBP

Figure 7. CXCL10 has a negative effect on myelination. $\boldsymbol{A}-\boldsymbol{E}$, Myelinating cultures were plated onto $\mathrm{PLL}-\mathrm{As}(\boldsymbol{A}-\boldsymbol{C})$ or $\operatorname{TnC}-\mathrm{As}(\boldsymbol{D}$, $\boldsymbol{E})$ and left untreated $(\boldsymbol{A}, \boldsymbol{D})$, or treated with CXCL10 neutralizing antibody $(2 \mu \mathrm{g} / \mathrm{ml}, \boldsymbol{C}, \boldsymbol{E})$. $\boldsymbol{F}$, Treatment of TnC-As cultures with CXCL10 neutralizing antibody led to an increase in myelination compared with untreated cultures. Myelinating cultures plated on PLL-As also received $10 \mathrm{ng} / \mathrm{ml} C X C L 10$ on day 12 and onward $(\boldsymbol{B}, \boldsymbol{F})$, which resulted in a reduction in myelination $\left({ }^{*} p<0.05\right) . \boldsymbol{G}$, Purified OPCs were double-immunolabeled with the 04 antibody and anti-MBP, in addition to A2B5 and anti-MOG, to assess differentiation after $\mathrm{CXCL} 10$ treatment for $7 \mathrm{~d}$, followed by staining on day $8(n=4)$. No differences in the percentage of differentiated cells were observed with CXCL10 treatment.

oligodendrocytes, which have already created a myelin sheath (data not shown). To determine whether mature purified oligodendrocytes extend larger processes in the presence of CXCL10, we measured the area of MBP-positive cells using ImageJ. CXCL10 did not affect the process spreading of the mature oligodendrocytes, since the area of MBP-positive cells was not significantly different from that of CXCL10-treated cells (1.7 arbitrary units compared with 1.85 arbitrary units). From these data we conclude that CXCL10 has little direct effect on isolated OPC behavior.

\section{Discussion}

\section{Astrocytes and their functional phenotype}

It is generally considered that reactive astrogliosis has detrimental effects on the repair of the CNS and that astrocytes in the noninjured normal CNS, termed quiescent, are generally supportive for neural cells (Ridet et al., 1997; Liberto et al., 2004; John et al., 2005; Williams et al., 2007). However, it is now thought that the reactive astrocyte phenotype is not a single uniform process, but a continuum of phenotypes which can be recognized in vivo, with at least three broad categories (Sofroniew and Vinters, 2010). These include mild to moderate reactive astrogliosis, severe diffuse reactive astrogliosis, and severe reactive astrogliosis with compact glial scar formation. Furthermore, it has been reported that astrocytes can express an activated phenotype that is more akin to mild astrogliosis and can be induced by cytokines (Liberto et al., 2004). How these stages of astrogliosis correlate to the astrocyte phenotype in vitro is not clear. To analyze how astrocytes influence myelination, we generated polarized astrogliotic phenotypes in vitro using two methods: (1) for a quiescent phenotype, astrocytes were plated on TnC (Holley et al., 2005), and (2) for an activated phenotype, astrocytes plated on PLL or TnC were treated with CNTF (Dallner et al., 2002; Liberto et al., 2004). Our findings formally demonstrate that polarization of astrocyte phenotype affects myelination.

\section{TnC and effect on astrocytes}

We demonstrate in this study that induction of a "quiescent" phenotype by plating astrocytes on TnC induces a soluble factor, subsequently identified as CXCL10, that inhibits myelination in vitro. This is an interesting observation because not only is CXCL10 implicit in the immunopathology of multiple sclerosis (MS) (Sørensen et al., 1999; Omari et al., 2005; Müller et al., 2010), but a recent study reported that failure of remyelination in MS is associated with increased expression of TnC (Mohan et al., 2010). We speculate that enhanced expression of TnC contributes to the development of demyelinated lesions by stimulating local expression of CXCL10, by astrocytes, as well as influencing OPC differentiation directly (Czopka et al., 2009). It is important to note that CXCL10 does not inhibit myelin completely, but dramatically reduces the number of myelin sheaths. This does not appear to reflect an effect of CXCL10 on OPC proliferation and differentiation, suggesting that it influences oligodendrocyte/axonal interactions, preventing myelin ensheathment.

The quiescent phenotype, which was defined as a phenotype resembling that of a resting astrocyte in the normal brain (Holley et al., 2005), does not appear to be a passive phenotype as it actively prevents myelination. However, this phenotype is reversible, since CNTF, a cytokine reported to induce astrocyte activation, returned the astrocyte to a supportive phenotype. Interestingly, control cultured astrocytes, which are often thought to be resting, actually support myelination to some extent, suggesting that they are activated.

\section{CNTF and activation of astrocytes}

Our data suggested that CNTF-treated astrocytes promoted myelination, which is likely to be via a secreted factor. CNTF is member of the $\alpha$-helical cytokine family (Guthrie et al., 1997; Weisenhorn et al., 1999) and plays an important role in brain development and injury (Stöckli et al., 1991; Lee et al., 1997). Although reports suggest that CNTF acts directly on oligoden- 
drocytes to favor their final maturation, it is unlikely to be the case in our cultures because the addition of CNTF to myelinating cultures plated on OECs had no promyelinating effect (Stankoff et al., 2002). This result suggested that the effect was more likely to be via the astrocyte monolayer. Furthermore, we demonstrated that OECs did not secrete any inhibitory factors for myelination, although we cannot totally exclude the possibility that OECs inhibit myelination by a contact-mediated effect. Even if this was the case, this effect could be overcome by soluble factors secreted by astrocytes (this report and Sørensen et al., 2008). Other reports have suggested that CNTF indirectly activates astrocytes to release a trophic factor for OPCs; however, in this study, the factor was shown only to be an OPC mitogen, and myelination was not studied (Albrecht et al., 2007). Conversely, in our experiments of mixed myelinating cultures, we did not find any evidence that CNTF was acting as a mitogen. It has also been reported that CNTF promoted neuronal survival by activating astrocytes (Albrecht et al., 2003); however, in our study, we found that neurite density and diameter were similar in all treatments, suggesting that survival was not affected.

CNTF treatment of the myelinating cultures plated on PLLastrocytes produced a dose-dependent effect in myelination. A similar bifunctional, concentration-dependent effect was reported for Schwann cell myelination after neuregulin 1 (Nrg1) treatment (Syed et al., 2010). In that study, the mechanism for the difference in myelination at high and low concentration of Nrg1 was due to a concentration-dependent differential activation of its receptor. High concentrations activated Erk pathways, but low concentrations activated the Akt pathways. A comparable mechanism may explain our results with the range of CNTF treatments.

Many reports demonstrate the pro-regenerative properties of cytokine-activated astrocytes, although the exact factor(s) secreted and targets are still not clear (Ridet et al., 1997; Liberto et al., 2004; Williams et al., 2007). Using microarray gene expression profiling of pure astrocyte monolayers, we did not find a large number of gene changes when comparison was made between PLL-As treated with and without CNTF. This may be because analysis was performed on pure astrocyte monolayers lacking myelinating cultures plated on their surface. Without the mixed-cell population from the myelinating cultures, we may be eliminating any cross talk between the various cell types (oligodendrocyte, neurons, stem cells, etc.). CNTF treatment may promote the secretion of an astrocyte factor which, in turn, affects oligodendrocyte lineage cells to secrete a factor that either directly or indirectly (via the astrocyte) influences myelination. It is also possible that CNTF could not activate astrocytes due to a lack of one of the components of its receptor. CNTF effects are mediated by a tripartite receptor complex consisting of the CNTF receptor $\alpha$, leukemia inhibitory factor receptor (LIFR), and gp130 (Lee et al., 1997; Sleeman et al., 2000). Signal transduction by CNTF requires that it bind first to $\mathrm{CNTF}$ receptor $\alpha$, permitting the recruitment of gp130 and LIFR, which leads to heterodimerization of the receptor subunits and tyrosine phosphorylation. It is known that neurons secrete CNTF receptor $\alpha$ (Sleeman et al., 2000); thus, it is possible that CNTF effects were not found from the microarray analysis of the monolayer of astrocytes because formation of the tripartite receptor failed, owing to the lack of one of its components. Future work will need to be performed on myelinating cultures plated on the various astrocyte phenotypes to address this question.

\section{CXCL10 and CNS biology}

A comparison of the microarray gene expression profile of pure astrocyte monolayers as polarized phenotypes (TnC-As vs CNTF-treated PLL-As) resulted in the identification of 15 significantly different probes. These included THBS4, CTGF, and CXCL10, all of which have been reported to play a role in myelination (Scott-Drew and ffrench-Constant, 1997; Sørensen et al., 1999; Omari et al., 2005; Stritt et al., 2009). qRT-PCR of these three genes on the cDNA from the various astrocyte phenotypes was performed for verification, and CXCL10 expression was the most significantly increased. For this reason, CXCL10 was chosen for further investigation.

CXCL10 is a small cytokine belonging to the CXC chemokine family that binds to CXCR3 and is implicated in the recruitment of leukocytes into the CNS (Balashov et al., 1999; Fife et al., 2001; Sørensen et al., 2002). CXCL10 plays a role in the pathogenesis of MS (Sørensen et al., 2002; Omari et al., 2005; Müller et al., 2010) and is highly upregulated in hypertrophic astrocytes surrounding active demyelinating MS plaques (Sørensen et al., 2002; Omari et al., 2005; Carter et al., 2007). In experimental autoimmune encephalomyelitis, an animal model of MS, levels of CXCL10 mRNA and protein increase significantly in the CNS at the peak of clinical disease and decline with recovery (Godiska et al., 1995; Glabinski et al., 1997; Fife et al., 2001). The source of CXCL10 in these models is astrocytes, rather than infiltrating monocytes (Ransohoff et al., 1993; Tani et al., 1996). Studies on CXCL10 ${ }^{-1-}$ and $C X C R 3^{-I-}$ mice provoked more severe clinical and histological symptoms and earlier onset in MS disease models compared with wild-type controls (Klein et al., 2004; Müller et al., 2007). Although current interpretations of the role of CXCL10 in MS action is mediated via the immune response (Müller et al., 2010) our data suggest that it may also act on oligodendrocytes to inhibit myelination. This is supported by our own RT-PCR data for the CXCL10 receptor, CXCR3, expression in rat OPCs (data not shown) and by the fact that human oligodendrocytes also express CXCR3 (Omari et al., 2005).

The data presented here demonstrate that the status of the astrocyte, be it reactive, activated, or quiescent, is crucial in determining the process of myelination. Interestingly, quiescent astrocytes secreted CXCL10, which did not appear to directly affect purified OPC differentiation but had the ability of oligodendrocytes to ensheath axons. These observations may have important implications with respect to the development of therapeutic strategies to promote CNS remyelination in demyelinating diseases.

\section{References}

Abney ER, Williams BP, Raff MC (1983) Tracing the development of oligodendrocytes from precursor cells using monoclonal antibodies, fluorescence-activated cell sorting, and cell culture. Dev Biol 100:166-171.

Albrecht PJ, Murtie JC, Ness JK, Redwine JM, Enterline JR, Armstrong RC, Levison SW (2003) Astrocytes produce CNTF during the remyelination phase of viral-induced spinal cord demyelination to stimulate FGF-2 production. Neurobiol Dis 13:89-101.

Albrecht PJ, Enterline JC, Cromer J, Levison SW (2007) CNTF-activated astrocytes release a soluble trophic activity for oligodendrocyte progenitors. Neurochem Res 32:263-271.

Alexander CL, Fitzgerald UF, Barnett SC (2002) Identification of growth factors that promote long-term proliferation of olfactory ensheathing cells and modulate their antigenic phenotype. Glia 37:349-364.

Balashov KE, Rottman JB, Weiner HL, Hancock WW (1999) CCR5(+) and CXCR3 $(+) \mathrm{T}$ cells are increased in multiple sclerosis and their ligands MIP-1 alpha and IP-10 are expressed in demyelinating brain lesions. Proc Natl Acad Sci U S A 96:6873-6878. 
Benjamini Y, Hochberg Y (1995) Controlling the false discovery rate: a practical and powerful approach to multiple testing. J R Stat Soc B 57:289-300.

Blakemore WF, Crang AJ (1989) The relationship between type-1 astrocytes, Schwann cells and oligodendrocytes following transplantation of glial cell cultures into demyelinating lesions in the adult rat spinal cord. J Neurocytol 18:519-528.

Bottenstein J, Hayashi I, Hutchings S, Masui H, Mather J, McClure DB, Ohasa S, Rizzino A, Sato G, Serrero G, Wolfe R, Wu R (1979) The growth of cells in serum-free hormone supplemented media. Methods Enzymol 58:94-109.

Bottenstein JE, Sato GH (1979) Growth of a rat neuroblastoma cell line in serum-free supplemented medium. Proc Natl Acad Sci U S A 76:514-517.

Breitling R, Herzyk P (2005) Rank-based methods as a non-parametric alternative of the $t$-statistic for the analysis of biological microarray data. J Bioinform Comput Biol 3:1171-1189.

Breitling R, Armengaud P, Amtmann A, Herzyk P (2004) Rank products: a simple, yet powerful, new method to detect differentially regulated genes in replicated microarray experiments. FEBS Lett 573:83-92.

Carter SL, Müller M, Manders PM, Campbell IL (2007) Induction of the genes for $\mathrm{Cxcl} 9$ and $\mathrm{Cxcl10}$ is dependent on IFN $\gamma$ but shows differential cellular expression in experimental autoimmune encephalomyelitis and by astrocytes and microglia in vitro. Glia 55:1728-1739.

Czopka T, Von Holst A, Schmidt G, ffrench-Constant C, Faissner A (2009) Tenascin $\mathrm{C}$ and tenascin $\mathrm{R}$ similarly prevent the formation of myelin membranes in a RhoA-dependant manner, but antagonistically regulate the expression of myelin basic protein via a separate pathway. Glia 57:1790-1801.

Dallner C, Woods AG, Deller T, Kirsch M, Hofmann HD (2002) CNTF and CNTF receptor alpha are constitutively expressed by astrocytes in the mouse brain. Glia 37:374-378.

Duncan D (1934) A relationship between axon diameter and myelination determined by measurement of myelinated spinal root fibres. J Comp Neurol 60:437-471.

Eddleston M, Mucke L (1993) Molecular profile of reactive astrocytesimplications for their role in neurologic disease. Neuroscience 54:15-36.

Eng LF, Ghirnikar RS (1994) GFAP and astrogliosis. Brain Pathol 4:229-237.

Faulkner JR, Herrmann JE, Woo MJ, Tansey KE, Doan NB, Sofroniew MV (2004) Reactive astrocytes protect tissue and preserve function after spinal cord injury. J Neurosci 24:2143-2155.

Fernaud-Espinosa I, Nieto-Sampedro M, Bovolenta P (1993) Differential activation of microglial and astrocytes in aniso- and isomorphic gliotic tissue. Glia 8:277-291.

Fife BT, Kennedy KJ, Paniagua MC, Lukacs NW, Kunkel SL, Luster AD, Karpus WJ (2001) CXCL10 (IFN-gamma-inducible protein-10) control of encephalitogenic CD4+ T cell accumulation in the central nervous system during experimental autoimmune encephalomyelitis. J Immunol $166: 7617-7624$

Franklin RJ, Crang AJ, Blakemore WF (1991) Transplanted type-1 astrocytes facilitate repair of demyelinating lesions by host oligodendrocytes in adult rat spinal cord. J Neurocytol 20:420-430.

Glabinski AR, Tani M, Strieter RM, Tuohy VK, Ransohoff RM (1997) Synchronous synthesis of alpha- and beta-chemokines by cells of diverse lineage in the central nervous system of mice with relapses of chronic experimental autoimmune encephalomyelitis. Am J Pathol 150:617-630.

Godiska R, Chantry D, Dietsch GN, Gray PW (1995) Chemokine expression in murine experimental allergic encephalomyelitis. J Neuroimmunol $58: 167-176$.

Gómez-Pinilla F, Vu L, Cotman CW (1995) Regulation of astrocyte proliferation by FGF-2 and heparan sulfate in vivo. J Neurosci 15:2021-2029.

Guthrie KM, Woods AG, Nguyen T, Gall CM (1997) Astroglial ciliary neurotrophic factor mRNA expression is increased in fields of axonal sprouting in deafferented hippocampus. J Comp Neurol 386:137-148.

Higginson JR, Barnett SC (2011) The culture of olfactory ensheathing cells (OECs) - a distinct glial cell type. Exp Neurol 229:2-9.

Holley JE, Gveric D, Whatmore JL, Gutowski NJ (2005) Tenascin C induces a quiescent phenotype in cultured adult human astrocytes. Glia 52:53-58.

Hudgins SN, Levison SW (1998) Ciliary neurotrophic factor stimulates astroglial hypertrophy in vivo and in vitro. Exp Neurol 150:171-182.

Jasmin L, Ohara PT (2002) Remyelination within the CNS: do Schwann cells pave the way for oligodendrocytes? Neuroscientist 8:198-203.
John GR, Lee SC, Song X, Rivieccio M, Brosnan CF (2005) IL-1-regulated responses in astrocytes: relevance to injury and recovery. Glia 49:161-176.

Klein RS, Izikson L, Means T, Gibson HD, Lin E, Sobel RA, Weiner HL, Luster $\mathrm{AD}$ (2004) FN-inducible protein 10/CXC chemokine ligand 10independent induction of experimental autoimmune encephalomyelitis. J Immunol 172:550-559.

Leadbeater WE, Gonzalez AM, Logaras N, Berry M, Turnbull JE, Logan A (2006) Intracellular trafficking in neurons and glia of FGF2, FGFR1 and heparan sulphate proteoglycans in the injured adult rat cerebral cortex. J Neurochem 96:1189-1200.

Lee MY, Deller T, Kirsch M, Frotscher M, Hofmann HD (1997) differential regulation of ciliary neurotrophic factor $(\mathrm{CNTF})$ and CNTF receptor alpha expression in astrocytes and neurons of the fascia dentate after entorhinal cortex lesion. J Neurosci 17:1137-1146.

Liberto CM, Albrecht PJ, Herx LM, Yong VW, Levison SW (2004) Proregenerative properties of cytokine-activated astrocytes. J Neurochem 89:1092-1100.

Maragakis NJ, Rothstein JD (2006) Mechanism of disease: astrocytes in neurodegenerative diseases. Nat Clin Pract Neurol 2:679-689.

McKeon RJ, Jurynec MJ, Buck CR (1999) The chondroitin sulfate proteoglycans neurocan and phosphacan are expressed by reactive astrocytes in the chronic CNS glial scar. J Neurosci 19:10778-10788.

Mohan H, Krumbholz M, Sharma R, Eisele S, Junker A, Sixt M, Newcombe J, Wekerle H, Hohlfeld R, Lassmann H, Meinl E (2010) Extracellular matrix in multiple sclerosis lesions: fibrillar collagens, biglycan and decorin are upregulated and associated with infiltrating immune cells. Brain Pathol 20:966-975.

Müller M, Carter SL, Hofer MJ, Manders P, Getts DR, Getts MT, Dreykluft A, Lu B, Gerard C, King NJ, Campbell IL (2007) CXCR3 signaling reduces the severity of experimental autoimmune encephalomyelitis by controlling the parenchymal distribution of effector and regulatory $\mathrm{T}$ cells in the central nervous system. J Immunol 179:2774-2786.

Müller M, Carter S, Hofer MJ, Campbell IL (2010) Review: The chemokine receptor CXCR3 and its ligands CXCL9, CXCL10 and CXCL11 in neuroimmunity-a tale of conflict and conundrum. Neuropathol Appl Neurobiol 36:368-387.

Nair A, Frederick TJ, Miller SD (2008) Astrocytes in multiple sclerosis: a product of their environment. Cell Mol Life Sci 65:2702-2720.

Noble M, Murray K (1984) Purified astrocytes promote the in vitro division of a bipotential glial progenitor cell. EMBO J 3:2243-2247.

Norenberg MD (1994) Astrocytic response to CNS injury. J Neuropathol Exp Neurol 53:213-220.

Omari KM, John GR, Sealfon SC, Raine CS (2005) CXC chemokine receptors on human oligodendrocytes: implications for multiple sclerosis. Brain 128:1003-1015.

Pekny M, Nilsson M (2005) Astrocyte activation and reactive gliosis. Glia 50:427-434.

Piddlesden SJ, Lassmann H, Zimprich F, Morgan BP, Linington C (1993) The demyelinating potential of antibodies to myelin oligodendrocyte glycoprotein is related to their ability to fix complement. Am J Pathol 143:555-564.

Ransohoff RM, Hamilton TA, Tani M, Stoler MH, Shick HE, Major JA, Estes ML, Thomas DM, Tuohy VK (1993) Astrocyte expression of mRNA encoding cytokines IP-10 and JE/MCP-1 in experimental autoimmune encephalomyelitis. FASEB J 7:592-600.

Reynolds BA, Weiss S (1996) Clonal and population analyses demonstrate that an EGF-responsive mammalian embryonic CNS precursor is a stem cell. Dev Biol 175:1-13.

Ridet JL, Malhotra SK, Privat A, Gage FH (1997) Reactive astrocytes: cellular and molecular cue to biological function. Trends Neurosci 20:570-577.

Rozen S, Skaletsky H (2000) Primer3 on the WWW for general users and for biologist programmers. Methods Mol Biol 132:365-386.

Scott-Drew S, ffrench-Constant C (1997) Expression and function of thrombospondin-1 in myelinating glial cells of the central nervous system. J Neurosci Res 50:202-214.

Silver J, Miller JH (2004) Regeneration beyond the glial scar. Nat Rev Neurosci 5:146-156.

Sleeman MW, Anderson KD, Lambert PD, Yancopoulos GD, Wiegand SJ (2000) CNTF and its receptors. Pharm Acta Helv 74:265-272.

Sofroniew MV (2009) Molecular dissection of reactive astrogliosis and glial scar formation. Trends Neurosci 32:638-647. 
Sofroniew MV, Vinters HV (2010) Astrocytes; biology and pathology. Acta Neuropathol 119:7-35.

Sommer I, Schachner M (1981) Monoclonal antibodies (O1 to O4) to oligodendrocyte cell surfaces: an immunocytological study in the central nervous system. Dev Biol 83:311-327.

Sørensen A, Moffat K, Thomson C, Barnett SC (2008) Astrocytes, but not olfactory ensheathing cells or Schwann cells, promote myelination of CNS axons in vitro. Glia 56:750-763.

Sørensen TL, Tani M, Jensen J, Pierce V, Lucchinetti C, Folcik VA, Qin S, Rottman J, Sellebjerg F, Strieter RM, Frederiksen JL, Ransohoff RM (1999) Expression of specific chemokines and chemokine receptors in the central nervous system of multiple sclerosis patients. J Clin Invest 103:807-815.

Sørensen TL, Trebst C, Kivisäkk P, Klaege KL, Majmudar A, Ravid R, Lassmann H, Olsen DB, Strieter RM, Ransohoff RM, Sellebjerg F (2002) Multiple sclerosis: a study of CXCL0 and CXCR3 co-localisation in the inflamed central nervous system. J Neuroimmunol 127:59-68.

Stankoff B, Aigrot MS, Noël F, Wattilliaux A, Zalc B, Lubetzki C (2002) Ciliary neurotrophic factor (CNTF) enhances myelin formation: a novel role for CNTF and CNTF-related molecules. J Neurosci 22:9221-9927.

Stöckli KA, Lillien LE, Näher-Noé M, Breitfeld G, Hughes RA, Raff MC, Thoenen H, Sendtner M (1991) Regional distribution, developmental changes, and cellular localization of CNTF-mRNA and protein in the rat brain. J Cell Biol 115:447-459.

Stritt C, Stern S, Harting K, Manke T, Sinske D, Schwarz H, Vingron M, Nordheim A, Knöll B (2009) Paracrine control of oligodendrocyte differentiation by SRF-directed neuronal gene expression. Nat Neurosci 12:418-427.

Syed N, Reddy K, Yang DP, Taveggia C, Salzer JL, Maurel P, Kim HA (2010)
Soluble neuregulin-1 has bifunctional, concentration-dependent effects on Schwann cell myelination. J Neurosci 30:6122-6131.

Talbott JF, Loy DN, Liu Y, Qiu MS, Bunge MB, Rao MS, Whittemore SR (2005) Endogenous Nkx2.2+/Olig2+ oligodendrocytes precursors cells fail to remyelinate the demyelinated adult rat spinal cord in the absence of astrocytes. Exp Neurol 192:11-24.

Tani M, Glabinski AR, Tuohy VK, Stoler MH, Estes ML, Ransohoff RM (1996) In situ hybridization analysis of glial fibrillary acidic protein mRNA reveals evidence of biphasic astrocyte activation during acute experimental autoimmune encephalomyelitis. Am J Pathol 148:889-896.

Thomson CE, Hunter AM, Griffiths IR, Edgar JM, McCulloch MC (2006) Murine spinal cord explants: a model for evaluating axonal growth and myelination in vitro. J Neurosci Res 84:1703-1715.

Thomson CE, McCulloch M, Sorenson A, Barnett SC, Seed BV, Griffiths IR, McLaughlin M (2008) Myelinated, synapsing cultures of murine spinal cord-validation as an in vitro model of the central nervous system. Eur J Neurosci 28:1518-1535.

Weisenhorn DM, Roback J, Young AN, Wainer BH (1999) Cellular aspects of trophic actions ion the nervous system. Int Rev Cytol 189:177-265.

Williams A, Piaton G, Lubetzki C (2007) Astrocytes-friends or foes in multiple sclerosis. Glia 55:1300-1312.

Yamamura T, Konola JT, Wekerle H, Lees MB (1991) Monoclonal antibodies against myelin proteolipid protein: Identification and characterization of two major determinants. J Neurochem 57:1671-1680.

Zhang SC, Lundberg C, Lipsitz D, O’Connor LT, Duncan ID (1998) Generation of oligodendroglial progenitors from neural stem cells. J Neurocytol 27:475-489. 